\title{
Ocular manifestations of childhood malnutrition- an overview
}

\author{
Rabindran $^{1}$, Gedam DS ${ }^{2}$ \\ ${ }^{1}$ Dr. Rabindran, Consultant, Neonatologist, Billroth Hospital, Chennai, India, ${ }^{2}$ Dr. D. Sharad Gedam, Professor \\ of Paediatrics, R. K. D. F. Medical College \& Associated S. R. K. University, Bhopal, MP, India.
}

Address for Correspondence: Dr. Rabindran, E- mail: rabindranindia@yahoo.co.in

\begin{abstract}
Vitamin A deficiency is the commonest cause of preventable childhood blindness in developing countries. Severity of xerophthalmia is directly proportional to the severity of malnutrition.
\end{abstract}

Key words: Protein energy malnutrition, Ocular manifestation, vitamin A deficiency, Malnutrition

Protein energy malnutrition is a range of pathological conditions arising from a coincident lack, in varying proportion of proteins and calories, occurring most frequently in infants and young children [1]. Childhood eye morbidity is 'Any eye condition that requires ophthalmic care which if untreated can often progress to sight threatening disease". Around $30 \%$ of under five children globally are malnourished \& it accounts for nearly $35 \%$ of childhood deaths world wide [2]. Deficiencies of retinol, folate, iron, magnesium and potassium are commonly found in malnutrition. However predominantly vitamin A deficiency, occasionally B-complex deficiency and rarelyprotein deficiency causes ocular damage. Children with night blindness have 3 times greater mortality compared to those without night blindness. Similarly presence of bitot's spots increases mortality by 9 times [3].

Vitamin A deficiency is the commonest cause of preventable childhood blindness in developing countries [4]. Clinical Vitamin A deficiency has apparent xerophthalmia and serum retinol levels below $0.35 \mu \mathrm{mol}$ whereas Subclinical Vitamin A deficiency presents as night blindness with no evidence of clinical xerophthalmia [5]. Vitamin A helps in the maintenance of healthy epithelial tissues. In its deficiency there is epithelial keratinization which become harder and resistant to wetting. Goblet cells which secrete mucous and maintain moistness is reduced. Retinal combines with opsin (found in the photosensitive part of rods in the retina) to form visual purple \& hence
Vitamin A deficiency produces "night blindness "where dark adaptation and ability to see in the dark are diminished. Young children are at higher risk for vitamin deficiency than adults because vitamin A requirements per unit of body weight $\{65 \mu \mathrm{g}(125 \mathrm{I} . \mathrm{U})\}$ is much greater than adults $\{12$ $\mu \mathrm{g}$ (36 $\mathrm{I} . \mathrm{U})\}$. Moreover children cannot store vitamin $\mathrm{A}$ in the liver [6].

Vitamin A deficiency may occur due to reduced intake of foods rich in vitamin A, decreased absorption due to diarrhoea, increased need as during infections like measles. Severity of xerophthalmia is directly proportional to the severity of malnutrition. Various signs of vitamin A deficiency in children include Night blindness $(\mathrm{XN})$, Conjunctival xerosis (X1A), Bitot's spots (X1B), Corneal xerosis (X2), Corneal ulcer covering less than $1 / 3$ of the cornea (X3A), Keratomalacia- Corneal ulcer covering at least $1 / 3$ of the cornea (X3B) \& Corneal scarring (XS) [7].

According to WHO, children over one year old diagnosed to have xerophthalmia are given 200,000 IU vitamin A orally for 2 consecutive days and later once after 4 weeks. For children $<1$ year half thedose is given in the same regime. Approaches for preventing vitamin A deficiency include nutritional education. Breast feeding should be motivated as Colostrum and breast milk contains vitamin A. Weaning foods rich in vitamin A like mango, papaya, spinach, carrots, sweet potatoes, red palm oil and dark green leafy vegetables should be given. Mothers also should take vitamin A 


\section{Editorial}

adequately. Overcooking and drying fruits in the sun should be done. Measles immunisation should be done.

Ocular abnormalities associated with beriberi (thiamine deficiency) include central scotomas and external ophthalmoplegias affecting cranial nerves III and VI. In Riboflavin deficiency there is congestion of limbal plexes, invasion of stroma and corneal neovascularization presenting as burning sensation, lacrimation and photophobia. Riboflavin deficiency also produces phlyctenularkerato conjunctiviti, rosacea keratitis and pannus of trachoma [8].

In nicotinic acid deficiency (pellagra) there is dermatitis, hyperpigmentation and hyperkeratosis involving eyelids. Optic neuritis and pigmentary maculopathy with loss of visual acuity and field may also occur. Severe vitamin B12 presents with ocular fundus findings of retinal haemorrhages, exudates and congested vessels. Retrobulbar neuritis is characteristic leading to central scotoma initially and later optic atrophy [8]. Ocular manifestations of vitamin $\mathrm{C}$ include subconjunctival haemorrhage, hyphaemas \& retinal haemorrhages. Iron $\&$ folic acid deficiency leads to anaemia which when severe presents as conjunctival pallor and retinopathy characterized by haemorrhages, cotton wool spots, roth spots and venous tortuosity [1].

Malnutrition makes body vulnerable to a wide range of infections and diseases, some of which may affect the eyes. Other eye diseases among malnourished children include lid oedema, chemosis, lid ecchymosis, Conjunctivitis, Trachoma, blepharitis \& predisposition to external infection [9]. Prompt diagnosis and timely intervention are must to prevent the ocular morbidities associated with childhood malnutrition. Schools are the best centres for effectively implementing comprehensive eye healthcare programme

Funding: Nil, Conflict of interest: None initiated. Permission from IRB: Yes.

\section{References}

1. Chandra Arvind, Gilbert Clare. When your eye patient is a child. Community eye health journal. 2010; 23(72): 1-3.ISSN 0953-6833.

2. Black R, Morris S, Bryce J. Where and why are 10 million children dying every year? Lancet june 2003; 361: 2226-2234.DOI: http://dx. doi.org/10. 1016/ S0140-6736(03)13779-8.

3. Sommer A, Tarwotjo I, Hussaini G, Susanto D. Increased mortality in children with mild vitamin A deficiency. Lancet. 1983 Sep 10;2(8350):585-8.

4. Custodio VI, Daneluzzi JC, Custodio RJ, Del Ciampo LA, Ferraz IS, Martinelli CE Jr, Ricco RG, Cupo P, Hering SE, Meirelles MS, Vannucchi H. Vitamin A deficiency among Brazilian school-aged children in a healthy child service. Eur J ClinNutr. 2009 Apr;63(4):485-90. Epub 2007 Nov 28.

5. Chiu M, Dillon A, Watson S. Vitamin A deficiency and xerophthalmia in children of a developed country. J PaediatrChild Health. 2016 Jul; 52 (7):699-703. doi: 10.1111/jpc.13243.

6. Kehinde AV ,Ogwurike SC, Eruchalu UV, Pam $\mathrm{V}$, Samaila E. School eye health screening in Kaduna Northern Nigeria.Nigerian journal of surgical research 2005;7(1-2):191-194.

7. Clare Gilbert.The eye signs of vitamin A deficiency; Community Eye Health. 2013; 26 (84): 66-67.

8. Sharma Seema, Bashisth BM, Kalhan Meenakshi, Goel Manish. Ocular infection in Kumar et al., Sch. J. App. Med. Sci., 2013; 1(5): 645-652.

9. Moore DB, Shirefaw W, Tomkins-Netzer O, Eshete Z, Netzer-Tomkins H, Ben-Zion I. Prevalence of xerophthalmia among malnourished children in rural Ethiopia. Int Ophthalmol. 2013 Oct; 33(5):455-9. doi: 10.1007/s10792-013-9715-9. Epub 2013 Jan 25.

\section{How to cite this article?}

Rabindran, Gedam DS. Ocular manifestations of childhood malnutrition- an overview. Int J Med Res Rev 2017; 5(11):925-926.doi:10.17511/ijmrr. 2017.i11.01 